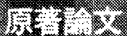

\section{持続腋窩部腕神経叢ブロックの \\ レントゲン造影による考察}

藤瀬久美子* 泉谷 良 * 生田まち子* 羽山憬一* 小松 彪* 留守信興* 山岡久泰*

要旨 Tuohy 針 $(17 \mathrm{G})$ とレントゲン不透過性硬膜外麻酔用カテーテルを用いて，持 続腋窩部腕神経叢ブロックを行い，手術および，一部は、術後鎮痛に使用した。術後 にレントゲン撮影を行い, カテーテル先端の位置の確認をし，その後，造影剤をカテ ーテルより注入して， sheath 内での広がりとブロックの効果との関係を調べた．その 結果，カテーテルは屈曲しやすく，鎖骨のレベルより中枢側へ越えることはなかった が，造影剤が sheath 内ではっきりした紡錘形の影像を示すほど，ブロックの効果は確 実であることが判った。

\section{Iはじめに}

上肢の手術は, 全身麻酔, 腕神経叢ブロック， 頸部硬膜外麻酔 ${ }^{1), 2)}$, 静脈内局所麻酔などいずれ の麻酔によっても可能である。しかし長時間に わたる切断指再接着術などでは, 従来の一回注 入法による腕神経鋠ブロックでは，その持続時 間に限界がある。この問題を解決するために， 静脈用テフロン針や硬膜外麻酔用カテーテルを 利用した持続腕神経叢ブロックの報告があ $3^{3) \sim 13)}$

我々もレントゲン不透過性硬膜外麻酔用カテ ーテルを腋窩部より挿入することにより，持続 腕神経叢ブロックを行い, 手術および，一部の 症例においては術後鎮痛に使用し, 術後にレン トゲンをとり，カテーテル先端の位置の確認お

* 大阪赤十字病院麻酔科
よび，造影剤による sheath 内での広がりを観察 した.

\section{II 対象および方法}

上肢の手術をうける ASA risk 1 ～2 15 名 を対象とした。年齢は11歳から57歳（平均 37.5 歳)，体重は $42.5 \mathrm{~kg}$ から $73 \mathrm{~kg}$ (平均 $57.3 \mathrm{~kg}$ ), 身 長は $142.5 \mathrm{~cm}$ から $176 \mathrm{~cm}$ (平均 $161.2 \mathrm{~cm}$ ) であった。 仰臥位にて上肢を外転，外旋させ，时部は約 90 度屈曲させたのち，大胸筋上腕骨付着部で烏口 腕筋の内側部やや中枢よりで，腋窩動脈に平行 に Tuohy 針の bevel を上向きにし,皮虐と約30 度の角度で中枢に向けて進めた。Click か Loss of resistence を確認後，レントゲン不透過性硬 膜外麻酔用カテーテルを挿入して固定した。手 術終了後, 15例中10例でレントゲンをとり，カ テーテルの先端の位置を確認し，その後， $30 \%$ アミドトリゾ酸ナトリウムメグルミン（60\%ウ ログラフィン ${ }^{\circledR}$ 生理食塩水か $0.25 \%$ ブピバカイ 
ンを等量混合したもの)を $10 \mathrm{ml}, 20 \mathrm{ml}, 40 \mathrm{ml}$ (一 部 $10 \mathrm{ml}, 20 \mathrm{ml}, 30 \mathrm{ml})$ とカテーテルより注入し, レントゲン撮影にてそれぞれの sheath の広がり を検討した。

\section{III 結果}

カテーテル捜入時は，スムーズに進むものも あったが, 数cm進入してから抵抗があり，そこ を強く押し進めると，またスムーズに進む症例 が多かった。我々の感じでは, 硬膜外麻酔のチ ュービングよりは，やや抵抗があるように思わ れた。カテーテルの先端が頸部方向に直進すれ ば，かなり広範な麻酔効果が得られるのではな いかと期待して，カテーテルをできるだけ進め てみたが，皮膚刺入部での硬膜外カテーテルの 目盛は $10 \mathrm{~cm}$ から $20 \mathrm{~cm}$ までさまざまで，平均 16.9 $\mathrm{cm}$ 挿入可能であった。

カテーテル挿入に際して paresthesia を認め たものはいなかった。

カテーテルの先端の位置は, 予想に反して, 鎖骨を越えることはなく，大胸筋，小胸筋の外 縁部に沿って屈曲し, 鳥口突起や上腕骨頭付近 に先端がある例が多かった（写真 $1 ， 2 ）$.

また sheath 内で屈曲し，刺入部近くにもどる 例もあった（写真 3 ). 造影剤を注入した結果は, 造影剤の量が増加するにつれ，紡鍾状に幅が広 がるとともに, 縦軸方向にも造影剂が浸潤して いつた（写真 $1 ， 2 ， 3)$. カテーテルの先端が 中枢に向っていた症例では，造影剂の中枢側へ の広がりが大きく（写真 1 )，末梢に向っていた 症例では，未梢側へ造影剤が広がる傾向があっ た（写真 3 ）.ブロックが有効であっても， sheath の造影像は異なり，40ml 注入で鎖骨を越え頸部 に達するものから（写真 1 ）, 鳥口突起の高さで 止まるものなどがあった（写真 $2 ， 3 ）$. しかし，

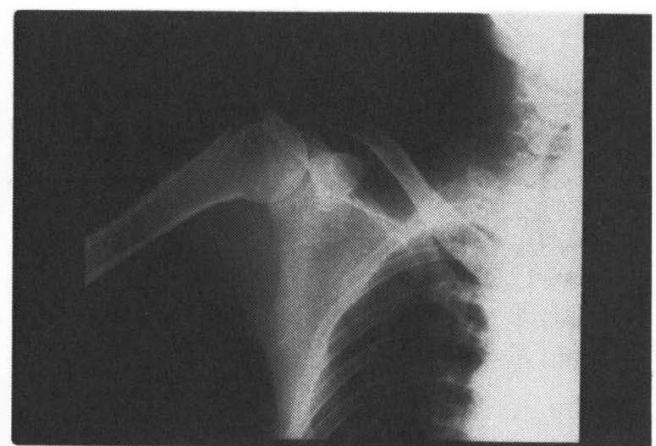

写真1-1 カテーテルは小胸筋外縁部で屈曲, 先端は中枢 に向かっている.

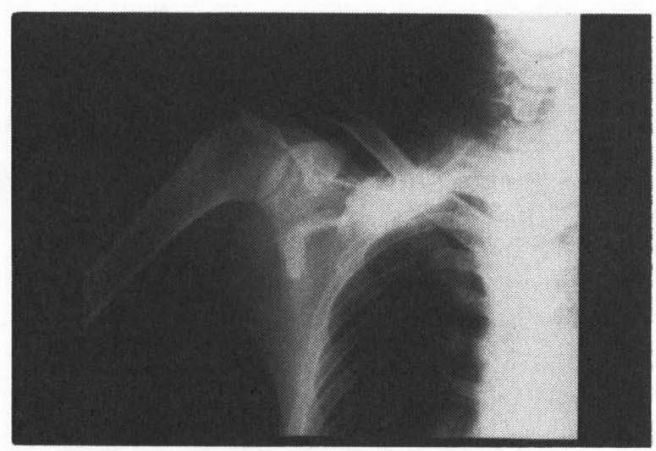

写真1-2 造影郕10me注入例

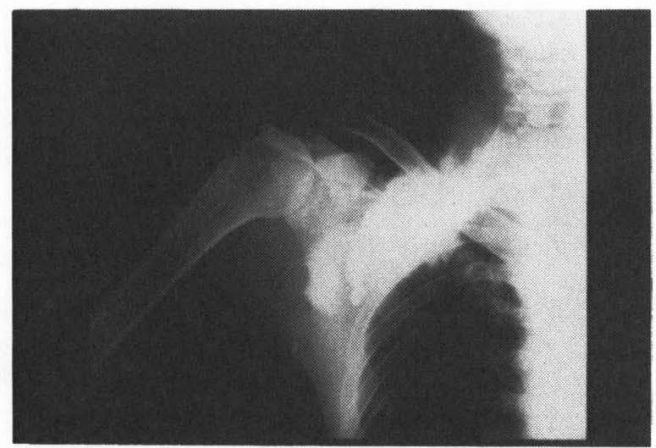

写真1-3 造影剤40m l注入例 造影率は銷骨を越えている

ほとんど鳥口突起の高さまでは造影されており， 腋窩神経, 筋皮神経が分岐するとされるレベル には達していると思われ，結果的にも，その領 域の analgesia は有効であった。しかし，これら 


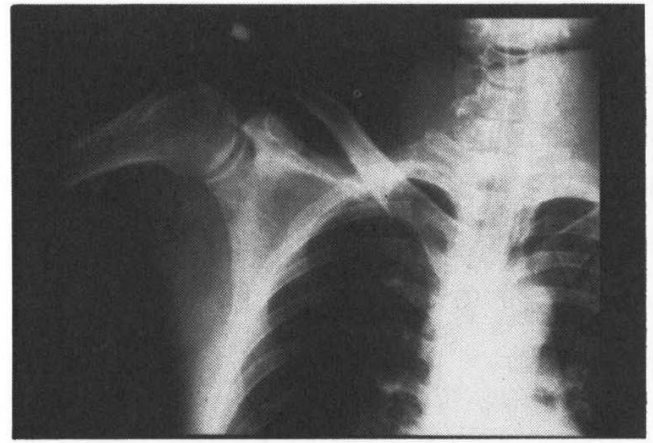

写真2-1 カテーテルは途中で屈曲している

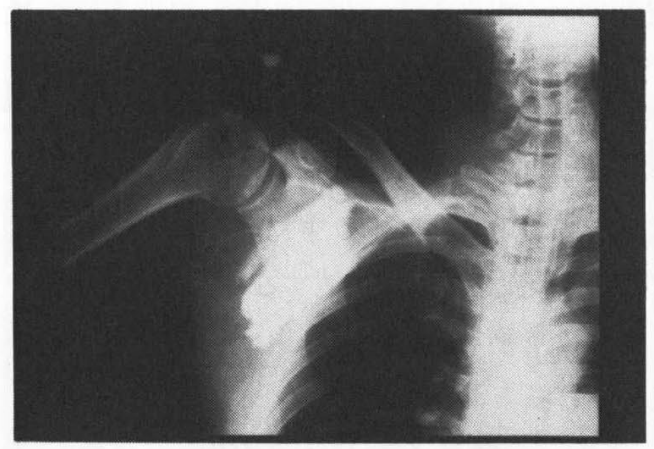

写真2-2 造影剤40ml注文でややいびつな造影郕

の領域の無痛が得られるまでの時間は, 30分以 上を必要とした．完全にブロックが有効であっ た例では，きれいな紡錘形を呈しているが（写 真 1,3 ), 不完全なブロックの効き方の例では, 造影像もややいびつな形を呈していることが多 かった（写真 2 )。無効例では, 明らかに sheath 内にカテーテルが入っていない影像を呈した（写 真 4 ).

\section{IV 考察}

多くの研究者が, 腕神経叢ブロックに関して 調べている，福家らは，Tuohy 針と硬膜外麻酔 用カテーテルを利用する本方法を考案したが， レントゲン的考察を行っていない ${ }^{12), 13) .}$

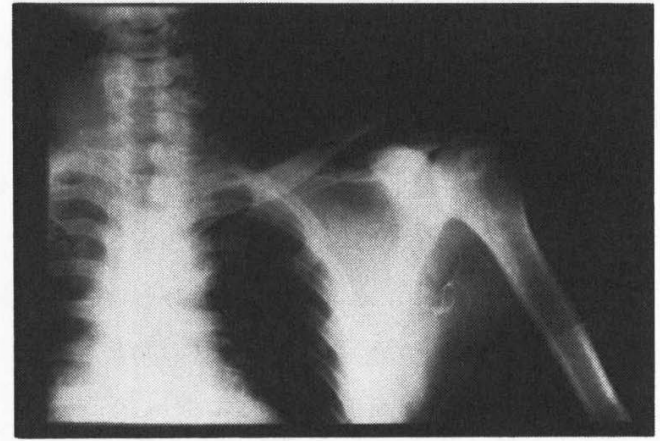

写真3-1 カテーテル先端が末梢に向かっている

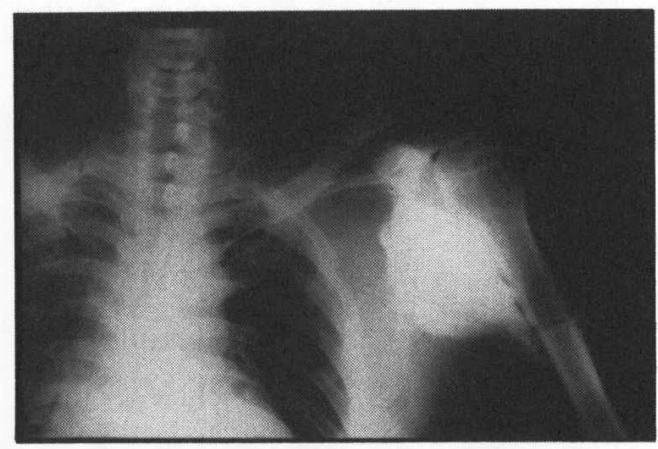

写真3-2 造影剤が末梢側に広がっている

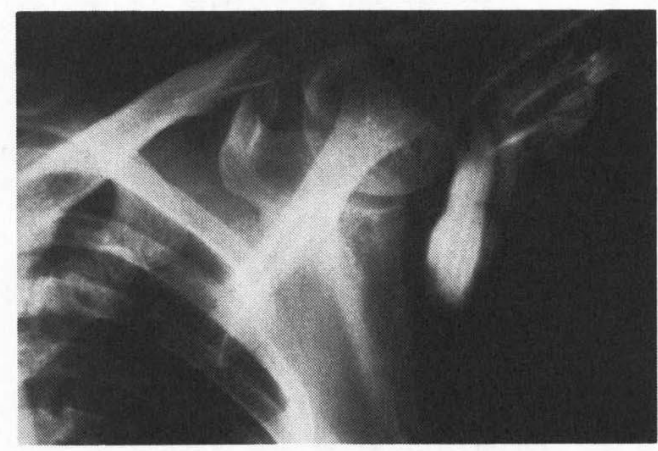

写真 4 sheath 内に造影剂が入っていない

Macmillan は硬膜外麻酔用カテーテルを利用 した持続腕神経叢ブロックの臨床使用を報告し ているが, 詳細は述べていない ${ }^{10)}$. De-Jong は ブロックの効果と局所麻酔薬の volume との関 
係を調べ，計算により最低 $42 \mathrm{ml}$ 必要と述べてい る ${ }^{14}$.Winnie は造影剂を使用して，注入部位，腕 の位置による影響など詳細に調べている ${ }^{15), 16)}$. 麻 酔の程度は，針の刺入点のレベルおよび局所麻 酔薬の volume に依存するが, 針先の高さが麻酔 範囲の決定上, volumeより重要であると，彼は 述べている．針先が腋窩のより高い場所になけ れば，上腕骨頭が局所麻酔薬の中枢への広がり を妨害するが，この時，腕を身体の脇へおろす と, 上腕骨頭による局所麻酔薬の流れの妨害を 取り除くことができる゙とも述べている，長櫓ら もエラスター針を使用した持続腋窩部腕神経叢 ブロックを行い, 造影剂を注入して, sheathの 横幅の広がりを得るためには volume が必要で あると述べている ${ }^{6)}$. Ang は flexible guide wire, introducer を利用して $80 \mathrm{~mm}$ のカテーテル を插入する方法を考案しており， flexible guide wire が100〜 150mm進むことが， click よりも正 しい位置にあることの証明になると述べてい $3^{17)}$.

針やエラスター針を利用した場合，針先の高 さには限度があると思われる。しかし，カテー テルを使用することにより，より高位の位置に 先端を留置でき, 烏口突起付近にまで到達すれ ば, 筋皮神経, 腋窩神経領域のブロックも確実 になると思われる。ところが，今回の造影の結 果をみると，肘部で屈曲，上肢を外転，外旋さ せた状態では, 確実にカテーテルを中枢側へ直 進させることは困難で, ほとんどの例でカテー テルをいくら進めても，いずれかの部位で屈曲 し，鎖骨のレベルを越えることはなかった。こ のカテーテルが屈曲する理由としては, 小胸筋 の鳥口突起付着部が狭いということ，そして今 回の体位によるアプローチでは，大胸筋，小胸 筋の緊張が強いということ，上腕骨頭による圧
迫など，さまざまな解剖学的原因が考えられる であろう。しかしながら，針やエラスター針に 比べて，本方法では中枢に近くカテーテルの先 端が進められることは確かで，今後は確実にカ テーテルが直進し，より中枢側に留置できる方 法を解剖学的に考慮すべきであろう。

\section{V ま と め}

Tuohy 針（17G） と硬膜外麻酔用カテーテル を利用して持続腋窩部神経叢ブロックを行い， 造影剤にて, カテーテルの位置, 造影像とブロ ックの効果とを検討した。

麻酔著効例では， sheathははっきりした紡鍾 形を呈していたが，カテーテルは届曲しやすく， 先端は鎖骨のレベルより中枢側へ越えることは なく, 鳥口突起付近に位置することが多かった。

今後は解剖学的に，より中枢にカテーテルを 進められる方法を検討すべきであろう。

(本論文の要旨は第 4 回日本臨床麻酔学会総 会にて報告した。）

\section{参考文献}

1）岩根正, 丸山正則, 松本美智子ほか：長時間の上肢手術に 対する頸部持続硬膜外麻酔, 麻酔, XXV : 815, 1976

2 ）萩原正洋, 木村基信, 唐沢重徳ほか：再接着術に対する頸 部持続硬膜外麻酔の経験，臨床麻酔，6:433，1982

3) Dekrey J. A., Schroeder C. F., Buechel D. R. : Continuous Brachial Plexus Block. Anesthesiology. 30 : 332, 1969

4) Selander D. : Catheter Technique in Axillary Plexus Block. Acta anaesth. scand. $21: 324,1977$

$5)$ Manriquez. R.G., Pallares V.: Continuous Brachial Plexus Block for Prolonged Sympathectomy and Control of Pain. Anesth. Analg. $57: 128,1978$

6）長橹巧, 大西春樹, 新山恵美子ほか：持続腋窩部腕神経叢 ブロック．臨床麻酤， $3: 1409,1979$

7 ) Rosenblatt R., Pepitone-Rockwell F., Mckillop M. J. : Continuous Axillary Analgesia for Traumatic Hand Injury. Anesthesiology. $51: 565,1979$

8 ) Vatashsky E., Aronson H. B. : Continuous Interscalene Brachial Plexus Block for Surgical Operations on the Hand. Anesthesiology. $53: 356,1980$ 
9) Hempel V., Finck M., Baumgărtner E.: A longitudinal Supraclavicular Approach to the Brachial Plexus for the Insertion of plastic Cannulas. Anesth. Analg. $60: 352,1981$

10) Macmillan R. R., West D. M., Desai K. M. : Brachial Plexus block in upper limb ischemia. Anesthesia. 37 : 215, 1982

11) Sada T., Kobayashi T., Murakami S. : Continuous axillary brachial plexus block. Can. Anaesth. Soc. J. $30: 201,1983$

12）福家伸夫, 阿久根透, 西立野研二ほか：Tuohy 針と硬膜 外用カテーテルを用いた持続腋窩ブロックの試み, 臨床麻 酔, $7: 389,1983$

13）福家伸夫：Tuohy 針と硬膜外カテーテルを用いた持続腋 曧ブロックの実際, 日本臨床麻酔学会誌, $4: 318,1984$
14) De Jong C. R. H. : Axillary Block of the Brachial Plexus. Anesthesiology. $22: 215,1961$

15) Winnie A. P., Radonjic R., Akkineni S. R. et al : Factors Influencing Distribution of local Anesthetic Injected into the Brachial Plexus Sheath. Anesth. Analg. $58: 225,1979$

16) Winnie A. P. : Perivascular Techiques of Brachial Plexus Block, PLEXUS ANESTHESIA, Churchill Livingstone, Edinburgh, 1984, 118 188

17) Ang E. T., Lassale B., Goldfarb G. : Continuous Axillary Brachial Plexus Block-A Clinical and Anatomical Study. Anesth. Analg. 63 : 680, 1984

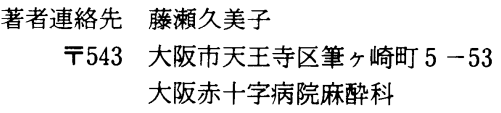

\title{
Roentgenographic Studies on Continuous Brachial Plexus Block with Axillary Approach
}

\author{
Kumiko FUJISE, Ryo IZUTANI, Machiko IKUTA, \\ Keiichi HAYAMA, Takeshi KOMATSU, Nobuoki TOMEMORI, \\ Hisayasu YAMAOKA
}

Department of Anesthesiology, Osaka Red Cross Hospital

Continuous brachial plexus block at the axilla is very effective method for a timeconsumed operation on upper extremity and post-operative pain management. We studied the location of a catheter-tip and the spread of local anesthetic solution in brachial plexus sheath using a radiopaque epidural catheter and a different amount of contrast medium. In almost all cases, the catheter roled up and its tip could never be located above the level of clavicle. A satisfactory block, however, could be obtained when at least $40 \mathrm{ml}$ of local anesthetic solution was injected and the spindle shaped sheath was seen in roentgenogram.

The Journal of Japan Society for Clinical Anesthesia Vol. 5 No. 2, 1985 